\title{
Digitalization of an Automating Batch Production using SCADA in Paint Industry
}

\author{
L. Chitra, Muzzammil Ahmad, Glory Mathew, Ramachandran
}

\begin{abstract}
Here Supervisory Control Acquisitions and Data is explained or discussed in this paper. In the paint industry - batch type production. It is to apply automation technique for the manufacturing of paints. In this paper, a computing design model for betterment of the functions of a batch processing plant which is capable of controlling all the analytical variables in the system and working durations of the previously created system operations which is applied to operations in a leading paint manufacturer plant. The focus of this work is a batch processing plant, multi-product, with wide list of projects, competing for many equipment stages at the manufacturing site. The production plant under discussion works in accordance with the principle of "order-based" production. Thus, this system can be segregated as a minimum term catalogue of a real case multi-product group processing plant. This paper also explains the digitalization of the process industries.
\end{abstract}

Keywords: Process Automation Control (PAC), Programmable Logic Controller, (SCADA) Supervisory Control and Data Acquisition System, Weight Transmitters (WT).

\section{INTRODUCTION}

SCADA is a type of firm regulation system that is used to audit and has some facilities using which we can control the infrastructure in several plants. The Programmable Logic Controller is used to automate the overall process and monitor.The application is implemented with a help of SCADA. In a batching system, the different configurations and solution for different challenges can be programmed [1]. The system is configured with a user-friendly recipe management system for the various production modifications or for different products. The flexible production processes can be made with uniform recipe automation considering all the safety standards. Modular master recipes type of configuration facilitates the creation of different batches and thus it improves the efficiency of the resources and the utilization of plant during the process and control in the Paint industry [2]. The consistency quality of the paint industry can be increased with the automatic batching system in reproducible batches [3]. The increase in transparency is assured by the closed loop operation of recording all data for the report as well as the integration of inventory and quality

Revised Manuscript Received on December 30, 2019.

Dr. L. Chitra *, Associate Professor, Department of Electrical and Electronics Engineering, Aarupadai Veedu Institute of Technology, Chennai, India.

Muzzammil Ahmad, Glory Mathew, Ramachandran, UG Students, Department of Electrical and Electronics Engineering, Aarupadai Veedu Institute of Technology, Chennai, India. data in the automation system. The updating and all changes are made simple to comprehend, for example, assignment, logbooks, and access protections are simple to update. This design principle helps the market condition to react for the dynamic changes of chemical industry. The utilization of production plants can be combined and can improve the production flexibility which results in a reduction of time to market .This also reduces the overall operating and lifecycle costs.

\section{PROPOSED METHODOLOGY}

\section{A. Design and Implementation of SCADA in the paint process}

To operate an industry in fully automation mode, PLC is the key which is widely using tool in an industries to control and read the entire process of the plant; while in running condition of the PLC ladder program the changes in the rungs are understandable by a skilled engineer only others cause difficulties to understand the operation[4]. So that SCADA system is implementing, through that the changes in the operation and process are easily understandable to a Client, by the differentiation in color of the motor, valves, filling of liquid in pipes and more are visible to all so that less skilled operator can also be control the plant [5].Fig.1 explains the batch process with the selected inputs and outputs.

The required main components to operate the paint manufacturing -batch process plant in automation are PLC controller Fig.2.Flow Chart of the Batch Process.

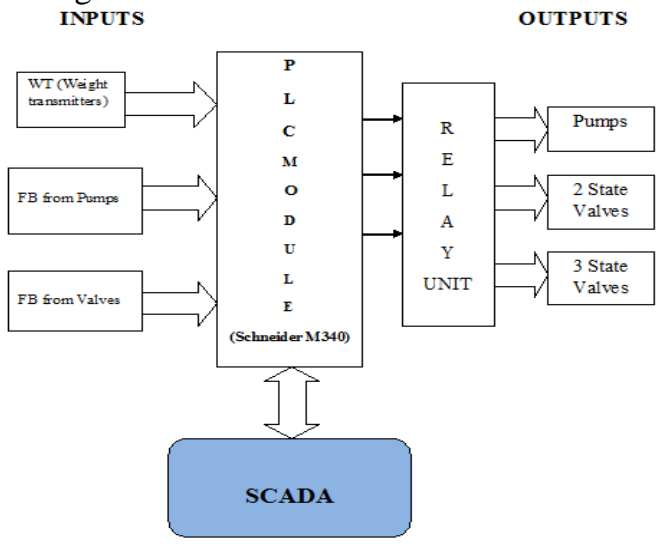

Fig. 1. Block Diagram of SCADA

(Schneider M340), no. of I/O ports (based on requirement), pumps, weight transmitters (load cell), two speed

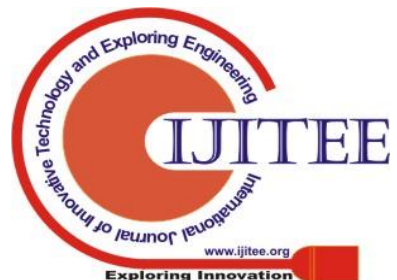


valves, three speed valves, etc.

The ladder diagram in PLC and Animation in SCADA needs specific programming concept with the details of the input and output devices to simulate the processes.

It is completely based on SCADA which is operated in paint batch process, we used Vijeo Citect software to which configure the plc to the system, create templates, I/O tags, animation works and more with this software address.

\section{PRODUCT DESCRIPTION}

\section{A. List of components}

To create a SCADA visual for a project, first has to know what are the components in it and the function of each component. These are the following components for our paint automation batch processes are:

- Pumps

- Load cells

- Weight transmitter (I 400)

- Normal valves

- 2 speed valves

- Storage tanks

- Paint collecting barrels, etc.

Based on these components have to design the graphics in SCADA software and configure the tags name with each component.

We are engaged in providing Single Change over Relay Module-8 Channel Relay Module. The product is provided in different specifications with all the data present in the forms as per the variegated needs of customers. This product is stringently checked by quality controllers against ever parameters of quality in order to supply a defect free range to customers.

\section{VIJEO CITECT SCADA SOFTWARE}

\section{A. SCADA -an Introduction}

SCADA is used to view all the alarms, trends $\mathrm{I} / \mathrm{O}$ and reports, and to use the same display information from each of the systems. This actually reduces the actual testing time or testing methods which is required for the project.

Computer system in which analyzing of RT data and collection of information takes place is called as SCADA. These are the systems in which auditing and controlling takes place such as Aerospace and Defense, Food \& Beverage, Oil \& Gas, Automotive, Infrastructure, Manufacturing, Water, Metals, Mining and Minerals, Waste Water.

It can be very simple as such the one which monitors the environmental situations and conditions of a single or two storey building or even if it's a skyscraper like power plants or a municipal telecommunication system or also a telecommunication system etc.,

This paint automation batch project, explains in detail the monitoring and controlling of the entire process of the plant in a single controller room. The changes happening in the plant can be visualized in the SCADA screen, i.e. the motor
Running mode, Stop mode and Trip conditions etc are visualized and it can be controlled by soft buttons.

\section{B. Applications}

SCADA has its application in a wide range such as to meet the demands of rigorous industries, and also to meet the seeking requirements of current startup firm sectors. SCADA is classic for a numerous industries such as Aerospace and Defense, Food \& Beverage, Oil \& Gas, Automotive, Infrastructure, Manufacturing, Water, Metals, Mining and Minerals, Waste Water.

\section{Remote Terminal Unit}

Intelligent Remote Terminal Unit or some std PLCs, can able to execute the basic logical processes without getting any aid or help from the super computers.

A programmable automation controller (PAC) is a small controller which includes the functions and abilities of a Computer based control or operating system which is quite similar to PLC. They are implemented in the SCADA systems to execute PLC and RTU functions. In many of the major substations SCADA usage has been abruptly increased like, "distributed RTUs" use information processors or substation PC's to transmit information with other devices for Input and Output, digital relays for protective purposes, PACs, and to communicate with the SCADA master instead of a normal RTU. When it comes to data collection and monitoring, SCADA is the solution. PLC and RTUs perform most control functions automatically in SCADA system.

\section{PROCESS SEQUENCES OF OPERATION}

The process sequence of the batch production of a paint industry is explained in detail in the flow chart. The flowchart explains starting from the selection of materials, weight measurement, selection of control valves etc till the process gets completed..The sequence of valve opening and closing with the defined logic is carried out.

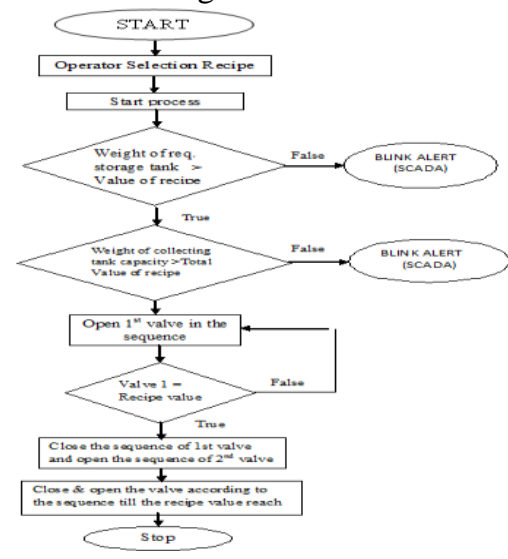

Fig. 2. Flowchart of batch process

\section{RESULT AND DISCUSSION}

Piping and Instrumentation diagram is a detailed graphical representation of the process control system that consist of piping, vessels, 
control valves and other instrumentation products and equipments of a system .The installation of the process control system is represented as a primary layout with a help of $\mathrm{P}$ and ID diagram.Fig.3 explains the piping and Instrumentation diagram of the batch process.

The COMOS software is used to draw the piping and Instrumentation diagram. .Digitalization of the equipments and valves can be done with this software.

The vessel data can be stored in the datasheet as shown in Fig.4. By clicking the vessel in the Piping and Instrumentation diagram the necessary values such as capacity of the tank, pressure etc can be saved as documents. Fig.5, fig. 6 explains the digitalization of the valves, monitoring of the batch process of a paint industry using SCADA screen.

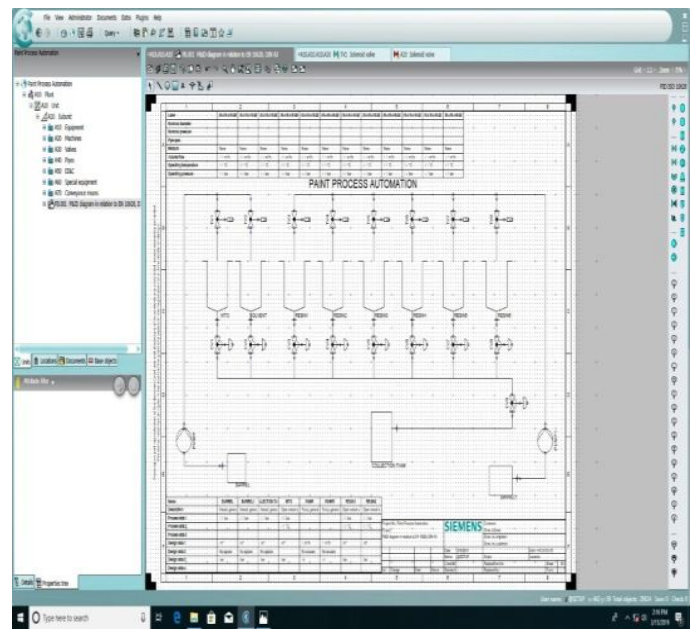

Fig. 3. Flowchart of batch process

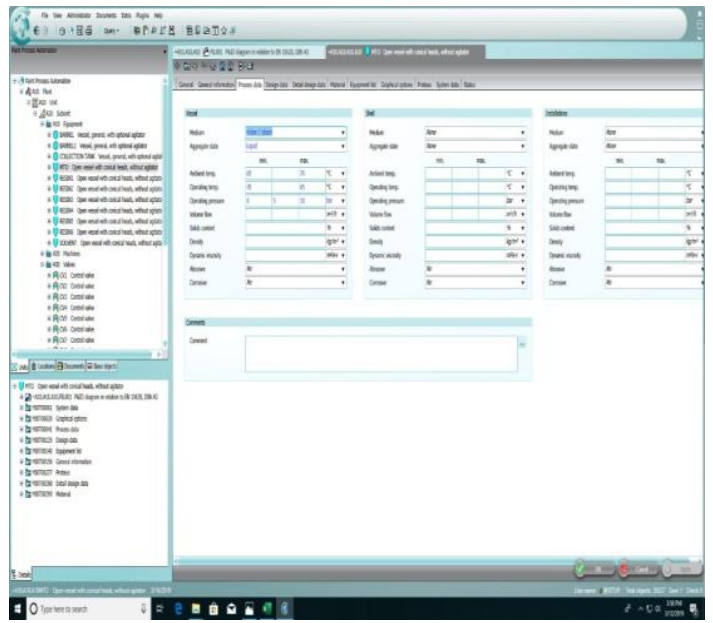

Fig. 4. Digitalisation of Process components such as vessels

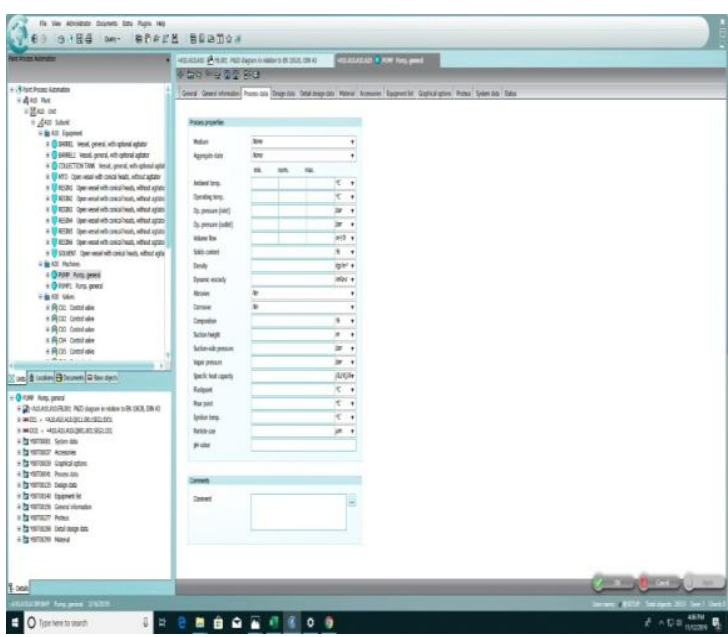

Fig. 5. Digitalisation of Process components such as valves

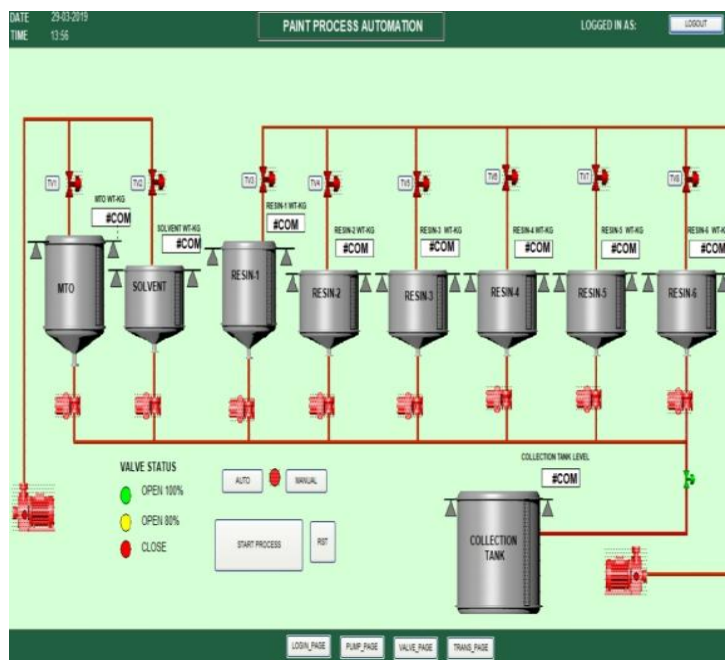

Fig. 6. Monitoring of the batch process of a paint industry using SCADA screen.

\section{CONCLUSION}

Mixing is the most crucial aspect of a paint industry, and that is the prime function and it is done by the use of PLC and SCADA. There are various methods available around the country but the main factors which makes to go with a particular method is as of follows like very high efficiency, huge turnover, first class quality and dependence of the firm which executes it. This project is implementing in a paint industry to produces different recipe of chemical products (paints). This paper presents the simulation of the paint automation processes in SCADA screen of batching process in paint industry. To operate a process in Automation PLC ladder program is quite enough, but the running process can't to view by client and as well as operator, so like SCADA software are using to understand the plant process by client and by this system it is easy to troubleshoot the problems and can be rectify the problems without going to shop floor. SCADA system is mainly using for large plant, in our project the plant is having wide area and n no. of 
controllers, to control the plant without this system is difficult. So we have designed SCADA system for our paint manufacturing company.

\section{REFERENCES}

1. Priyanka Sandokar, Nikita Vaidya, Tejaswini Jogekar, "Automation based industrial plant using SCADA", International Journal of Latest Engineering and Management Research (IJLEMR), 1(3), Apr.2016, pp.20-24.

2. M. Niranjan, N. Madhukar, A. Ashwini, J. Muddsar, M. Saish M, "IOT Based Industrial Automation", IOSR Journal of Computer Engineering e-ISSN: 2278-0661,p-ISSN: 2278-8727,2017, pp.36-40.

3. L. Chitra, "IOT-based oil condition monitoring of wind turbine gear boxes with smart sensor technology", The International Journal of Electrical Engineering and Education, May.2019.

4. T. Prabhu, "Study Of Superconducting Fault Current Limiter (Sfcl) Technology For Optimal Power Plant Performance And Grid Expansion", International Journal of MC Square Scientific Research, 5(1), Nov.2013.

5. . Sadeque Reza Khan Professor Dr. M. S. Bhat, "GUI based industrial monitoring and control system", In Power and Energy Systems: towards Sustainable Energy, Mar.2014, pp.1-4.

\section{AUTHORS PROFILE}

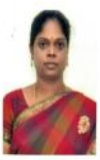

Dr. L. Chitra is an Associate Professor and Head in the department of EEE at Aarupadai Veedu Institute of Technology. She received her Bachelor Degree in Electronics and Instrumentation Engineering. She received her Master's Degree in Power Electronics and Drives in Anna University. She completed her PhD in Sathyabama Institute of Science and Technology in the field of Micro Electro Mechanical Systems for sensor design. Her research area includes MEMS, Renewable Energy, Process control, Sensors and Smart Sensors. She has published more than fifteen papers in International Conferences and Journals. She has a teaching experience of more than 18 years. She has received MNRE fund of Rs.1,50,000 for National Conference on Emerging Trends in New Renewable Energy Sources in the year 2014. She has also received a fund of Rs.1,00,000 from Unnat Bharat Abhiyan for Mobile Reverse osmosis based water purification system using Solar PV source for rural India in year 2019. She has also received a fund of Rs.50,000 from Unnat Bharat Abhiyan for DC Micro Grid based Solar PV generation to supply power to street lamp and common utilities in a village.

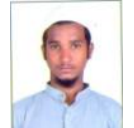

Muzzammil Ahmad has completed his Bachelor's Degree at Aarupadai Veedu Institute of Technology, Vinayaka Mission's Research Foundation, Chennai. He is one of the notable student in his college, for his interest in the field of PLc and Mechatronics systems. He has worked on many projects related to Renewable Energy, PLC, smart grid, etc., His current research interests include power electronics, renewable energy, Robotics, PLC, etc., He got placed in Hitachi during his seventh semester

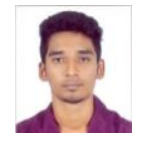

Glory Mathew has completed his Bachelor's Degree at Aarupadai Veedu Institute of Technology, Vinayaka Mission's Research Foundation, Chennai. He has worked on many projects related to Renewable Energy, PLC and its applications, etc.,. He is one of the notable student in his college, for his interest in the field of Automation and Renewable Energy. His current research interests include power electronics, renewable energy, SCADA, PLC, etc.,

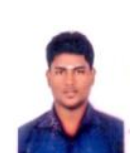

Ramachandran has completed his Bachelor's Degree at Aarupadai Veedu Institute of Technology, Vinayaka Mission's Research Foundation, Chennai. He is well known student in his college for his excellent Skills in his field of interest. He has worked on many projects related to Mechatronics systems, PLC, smart grid, etc., His current research interests include Robotics and Automation, renewable energy, PLC, etc., 